International Journal of Child, Youth and Family Studies (2013) 3: 328-336

\title{
THE IMPACT OF YOUTH-ADULT RELATIONSHIPS ON RESILIENCE
}

\section{Michael Ungar}

\begin{abstract}
Distinguishing between population-wide strengths and processes associated with youth resilience, this paper shows that engaging and transformative youth-adult relationships exert the greatest impact on youth who are the most marginalized. This pattern of differential impact demonstrates that the factors that contribute to resilience, such as engagement, are contextually sensitive. For youth with the fewest resources, engagement may influence their life trajectories more than for youth with greater access to supports. Case material and research that shows the link between resilience and engagement of youth with adults is discussed as a way to show that resilience is not an individual quality, but instead a quality of the interaction between individuals and their environments. The benefits of youth-adult partnerships are realized for marginalized youth when specific conditions that promote interactions that contribute to resilience are created.
\end{abstract}

Keywords: resilience, adult-youth partnerships, marginalized youth, youth engagement

Michael Ungar, Ph.D. is the Killam Professor of Social Work and Co-director of the Resilience Research Centre at Dalhousie University, 6420 Coburg Road, PO Box 15000, Halifax, Nova Scotia, Canada, B3H 4R2. E-mail: Michael.ungar@dal.ca 
Tak-Yan emigrated to northern California from China with his mother and stepfather when he was 3 years old. It was shortly after the family had settled that Tak-Yan's father was jailed for a violent crime and his mother began to drink heavily. Tak-Yan was eventually removed from his mother's care and spent the next five years in a series of foster and group homes. Once returned to his mother, he suffered severe emotional neglect and eventually turned to delinquent peers for support. A night in jail and a six-month probation order when he was 15 caused Tak-Yan to reconsider his life. At about this same time, Tak-Yan was contacted by an outreach worker from a church-sponsored community organization with strong links to TakYan's ethnic community. That worker recognized Tak-Yan's potential and provided him with opportunities to participate in community activities, including efforts to support younger children who were just beginning to get in trouble with the law. The mentorship and the opportunity to make a real contribution were both attractive to Tak-Yan who quickly changed peer groups.

While Tak-Yan was motivated to change, it was the structure provided by a court order, coupled with the opportunity for mentorship and recognition from adults that created the conditions that facilitated a change in his life course. Furthermore, Tak-Yan's identification with his outreach worker and realistic opportunities to find a powerful identity as one who helps others were crucial factors in Tak-Yan's self-description of his resilience. In Tak-Yan's case, there was an easily identifiable set of protective factors that were responsive to the types of adversity he faced. It is this interaction between an individual child's risk exposure and engagement in emancipatory relationships with adults that is the focus of this article.

\section{A Social Ecological Understanding of Resilience}

Despite decades of resilience research, there continues to be ambiguity in how to define and measure positive development in contexts of adversity. Part of the reason is that there has been confusion describing the difference between a strength or asset that benefits an entire population regardless of whether risk factors are present, and protective and promotive factors and processes that respond to specific risks (Wright \& Masten; 2006; Ungar, 2012). In the first instance we talk about strengths contributing to well-being; in the latter we talk about resilience under conditions of adversity. The distinction can be difficult to make because a strength (e.g., the engagement of young people in relationships with adults through transformative collaborations) may benefit all youth to some degree whether they are at risk or not. This same strength (engagement with adults) for a child like Tak-Yan, will, however, exert a greater impact when that child has few other ways to cope with adversity (Abrams \& Aguilar, 2005). In this regard, a strength such as youth engagement can exert a differentially larger impact on the developmental outcomes of marginalized young people.

The distinction between a strength in one context and a factor that contributes to resilience in another depends upon (a) the amount of stress the individual is exposed to (higher levels of stress make the likely impact of engagement even greater), and (b) the amount of change that can be expected in a child's life trajectory. Therefore, typical of many factors that increase resilience, youth engagement is a protective factor against psychological and social 
International Journal of Child, Youth and Family Studies (2013) 3: 328-336

problems in circumstances where young people experience adversity, but is less influential when risk is low (Shernoff \& Schmidt, 2008).

This pattern of differential impact shows that the factors that contribute to resilience are contextually sensitive and therefore difficult to identify without assessing the real-world barriers children experience to psychosocial development (Thomlison, 1997). A social ecological understanding of resilience is meant to address this problem. Resilience is understood as more than a set of individual competencies under stress: the higher the level of adversity children experience, the more they benefit from resources that facilitate successful pro-social forms of coping such as an empowering relationship with a caring adult. It is the optimal functioning of the young person's environment that is the most important factor in deciding children's resilience rather than the specific capacities of children themselves (Ungar, 2011b). As TakYan's life story shows, without the opportunity to take advantage of a healthy environment, a child will use maladaptive forms of coping to maintain well-being.

While recent theorizing has suggested that resilience is the interaction between individuals and their environment, the tendency has been to emphasize that both are equally influential on developmental outcomes. Herein lies one of the reasons for problems conceptualizing resilience. In better-resourced environments, individual talents are likely more influential on developmental outcomes because the child's personal expression of competency has many opportunities to be noticed. For less stressed individuals, the person and the environment may count equally because the environment is rich with resources and the individual has many different opportunities to succeed. However, when stress is much higher and risk factors accumulate, the environment is often impoverished. For the child to succeed and have her talents recognized, her environment must provide an exceptionally effective protective factor (such as an engaging adult who cares about the child's success) in order to counteract the negative effects of a socially toxic home, school, or community. While personal qualities still matter, they matter much less when they have no special place for expression. In other words, under conditions of great adversity, it is the quality of the environment that makes it possible for a child to succeed rather than the child's talents.

This, then, is why a relational factor such as the engagement of young people with adults can account for far more of the variance in developmental trajectories among stressed youth than individual factors. Without the relationship, individual capacity would lie dormant, or manifest as maladaptive forms of delinquent and disordered behaviour typical of individuals who cope in dangerous environments (Kurtines et al., 2008). A social ecological interpretation of resilience provides a way of understanding this complex pattern of influence that families, schools, and communities have on the processes promoting resilience that children like Tak-Yan use to survive.

\section{The Importance of Youth-Adult Relationships}

In contexts of risk, relationships are crucial to mitigating the negative impact of toxic environments. Resilience, the capacity to overcome adversity, is facilitated by those who engage with the child (Masten, 2001; Rutter, 2012). To illustrate, Yates, Egeland, and Sroufe (2003) showed through their 25-year longitudinal study that it is necessary to appreciate the 
International Journal of Child, Youth and Family Studies (2013) 3: 328-336

interactional processes that lead to greater resilience during a child's development. These processes begin early, they argue:

[T]he successful negotiation of early developmental issues provides a foundation for the process of resilience among disadvantaged youth. This process originates in early transactional exchanges between the child and her or his caregiver that scaffold the child's developing capacities for adaptive emotion regulation, social engagement, and positive expectations of the social world and of the self. (pp. 257-258)

These exchanges, however, do not need a strong child to succeed. In the case of children who have been badly neglected, such as Romanian orphans adopted by well-resourced families in Britain, it was the sustained capacity of the caregivers and professional supports that created conditions for even the most vulnerable of these children to achieve developmental gains (Barke, 2006). While one could argue that each orphan had the capacity to grow, the real potential to stimulate this growth lay dormant while the child was in the orphanage. It was changes to the environment, not changes to the child, which best accounted for better than expected outcomes.

Engagement, however, is not chosen by the child as a pathway to resilience in all instances. Instead, as Wyman (2003) has observed, children may accurately appraise their situations as dangerous and perceive adults as unreliable, resisting their influence. To maintain their well-being children withdraw emotionally from adults who approach them with offers of help. This pattern of hidden resilience (Ungar, 2004), or what is wrongly perceived as maladaptive coping, speaks to the need to understand the complex interactions between children and their environments.

It is for this reason that resilience can be defined as the individual's ability to navigate to resources, as well as the capacity of the individual's environment to provide resources that protect the child in ways that are meaningful (Ungar, 2008). Unless the child is empowered to negotiate for what he needs, the resources that are provided are unlikely to be used (Bottrell, 2009). It is for this reason that adults who engage children in processes that let them be heard and empowered in the design of their care plans are likely to help children maximize the benefit of the relationship. As Wyman (2003) explains, "processes that are beneficial to children in one context may be neutral, or even deleterious, in another” (p. 314). In contexts where children experience limited access to resources, the provision of a relationship that is transformative and empowering may successfully counter a negative life trajectory (Lerner \& Overton, 2008). In particular, as Delgado (2006) shows, creating opportunities for youth to become leaders benefits the disadvantaged child the most.

Caution is required, however, when describing the nature of youth-adult relationships that contribute to positive developmental outcomes. In a study of 500 middle-class families in the United States (Jones \& Schneider, 2009), it was shown that parents could have a positive influence on school outcomes when they involved themselves in activities with their children that were not focused on improving educational performance (weekend camping trips were more predictive of adolescents' school performances than reviewing homework assignments with them). Overly protective parenting that was too controlling of children's choices was associated with lower grade point averages among adolescents, while indirect academic pursuits such as 
sharing an activity together, especially those done with a mother, actually had a positive impact on school performance. Furthermore, the quantity of time parents spent with their adolescent was not related to school performance either. Instead, it was the quality of the interactions, and the coaching parents provided youth on life choices, the expectations they conveyed for school completion, and the undertaking of family activities outside of school that predicted school achievement. While the sample in the 500-family study was not a population facing extreme adversity, the findings support the notion that factors that predict positive youth development involve relationships with caregivers that are matched to children's needs rather than imposed on them by adults who think they know best.

Research such as this has shown remarkably similar results to that of a study by Ungar, Liebenberg, Armstrong, Dudding, and van de Vijver (2013) of 497 multiple service users, all of whom were children experiencing adversity. In that study, it was not the quantity of services, but the quality of relationships between a single service provider and youth that was most predictive of functional outcomes like school engagement. Resilience, as measured by the Child and Youth Resilience Measure-28 (Ungar \& Liebenberg, 2011) was the mediating factor between service quality and engagement in pro-social activities. Here, youth-adult relationships that were attentive to the needs of young people, engaged their voice in decisions affecting them, encouraged negotiation rather than the imposition of pre-selected interventions, and sustained equal participation when reasonable to do so, were all contributing factors to young people experiencing benefits from these relationships.

\section{Contextual and Cultural Specificity}

The nature of these relationships, however, is contextually and culturally specific. Patterns of interaction that produce healthy outcomes are best investigated using methods that encourage the discovery of unnamed processes that contribute to resilience. For example, a study of positive deviance done by Diaz (2010) of young Latina women who, despite numerous risk factors for an early pregnancy (e.g., an older boyfriend and a mother who had had a child when young) were enrolled in university and had avoided pregnancy, found several factors that predicted their success as outliers among their peers. While it was initially thought that these girls would have had better access to sexual health education or talked more frequently about sex with their mothers, in fact neither pattern was observed. Qualitative interviews showed that a number of communication practices were responsible for the women's success, almost none of which related directly to their sexual behaviours. Among the protective practices identified were:

- Parents emphasized the importance of finishing school to their daughters.

- Parents set clear expectations regarding work and home, and in-class and out-of-class activities in consultation with their children.

- Parents emphasized the benefits of extracurricular activities and having clear goals for the future.

- Each young woman had the support of a trusted male member of her family or community who provided affirmation and guidance.

- When talking about a potential pregnancy, mothers emphasized the gains to be achieved by delaying pregnancy rather than describing pregnancy as a failure. 
International Journal of Child, Youth and Family Studies (2013) 3: 328-336

It is worth noting that the unconventional practice of talking very little about sex and much more about school was a contextually specific strategy employed by adults to engage these young women in their education. Arguably, the youth-adult relationship was strengthened through the positive focus and future orientation of the interactions.

These examples suggest that youth will engage with adults in constructive patterns of behaviour that promote well-being when adults offer themselves as resources in ways that young people value. In this sense, the youth-adult relationship becomes a resource promoting resilience when it is made available in ways that respect the young person's negotiations for a level or type of support that matches her understanding of what she needs.

\section{Facilitating Youth-Adult Partnerships}

The benefits of youth-adult partnerships are realized for marginalized youth like Tak-Yan when conditions are created that promote interactions that contribute to resilience (they help youth navigate and negotiate more effectively). As Zeldin, Camino, and Mook (2005) explain, "youth engagement in traditionally adult roles has the potential to maximize youth sense of community while concurrently ensuring that youth have the opportunity to be active agents in their own development and to enhance the social organizations in which they live” (p. 122). Zeldin et al. identify six managerial guidelines that create conditions that promote positive development among at-risk youth. Adapted to the present focus on resilience and reflecting the research, the following processes that make youth-adult relationships transformative through engagement can be identified:

- Gain clarity and consensus on the purpose of including youth in decision-making processes in their families, schools, and communities.

- Mobilize and coordinate a group of diverse stakeholders so that youth are assured of advocates who can support them in their choices. In addition to youth as participants, adult stakeholders are also needed to mobilize support and avoid decisions being ignored.

- Create favourable organizational narratives about the advantages of including youth voices in decision-making processes. It is important that families, schools, and communities develop a positive attitude towards youth engagement and document anecdotal evidence for its effectiveness.

- Construct explanations for why youth should have a say over the decisions that affect them.

- Affirmatively address issues of role and power while acknowledging the asymmetrical power between youth and adults. Work to find solutions to balancing this power while still providing youth with the structure and support they require to make good decisions within their means.

- Institutionalize new roles for youth and make these the norm through mandated structural changes to families, schools, and communities.

Each of these strategies positions the adult in a more equal relationship with the youth they are trying to engage. If successful, the evidence cited earlier suggests that the result will be an increase in a young person's social capital and access to the resources that predict resilience when facing adversity (Ungar, 2011a). 
International Journal of Child, Youth and Family Studies (2013) 3: 328-336

\section{Conclusion}

The value of transformative youth-adult relationships is that they offer the most vulnerable youth a resource for well-being. When these relationships facilitate access to prosocial expressions of personal talents, the result is likely to be adaptive behaviour among youth who face multiple risk factors. In this sense, these young people's resilience is the result of the quality of their engagement with adults and not a personal trait. This shift to a social ecological understanding of resilience avoids blaming young people who resort to maladaptive behaviour to survive. Instead, we see that it is the ability of their families, schools, and communities to make relationships with adults available that determines children's success. 
International Journal of Child, Youth and Family Studies (2013) 3: 328-336

\section{References}

Abrams, L. S., \& Aguilar, J. P. (2005). Negative trends, possible selves, and behavior change: A qualitative study of juvenile offenders in residential treatment. Qualitative Social Work, 4(2), 175-196.

Barke, E. J. (2006). Do the effects of early severe deprivation on cognition persist into early adolescence? Findings from the English and Romanian Adoptees Study. Child Development, 77(3), 696-711.

Bottrell, D. (2009). Understanding 'marginal' perspectives: Towards a social theory of resilience. Qualitative Social Work, 8(3), 321-340.

Delgado, M. (2006). Designs and methods for youth-led research. Thousand Oaks, CA: Sage.

Diaz, A. (2010). A positive deviance inquiry of communicative behaviors that influence the prevention of Hispanic teenage pregnancy. Unpublished doctoral dissertation, The University of Texas at El Paso.

Jones, N., \& Schneider, B. (2009). Rethinking the role of parenting: Promoting adolescent academic success and emotional well-being. In N. E. Hill \& R. K. Chao (Eds.), Families, schools, and the adolescent (pp. 73-90). New York: Teachers College Press.

Kurtines, W. M., Ferrer-Wreder, L., Berman, S. L., Cass Lorente, C., Briones, E., Montgomery, M. J., et al. (2008). Promoting positive youth development: The Miami Youth Development Project (YDP). Journal of Adolescent Research, 23(3), 256-267.

Lerner, R., \& Overton, W. F. (2008). Exemplifying the integrations of the Relational Developmental System: Synthesizing theory, research, and application to promote positive development and social justice. Journal of Adolescent Research, 23(3), 245-255.

Masten, A. S. (2001). Ordinary magic: Resilience processes in development. American Psychologist, 56(3), 227-238.

Rutter, M. (2012). Resilience: Causal pathways and social ecology. In M. Ungar (Ed.), The social ecology of resilience: A handbook of theory and practice (pp. 33-42). New York: Springer.

Shernoff, D. J., \& Schmidt, J. A. (2008). Further evidence of an engagement-achievement paradox among U. S. high school students. Journal of Youth and Adolescence, 37, 564580.

Thomlison, B. (1997). Risk and protective factors in child maltreatment. In M. W. Fraser (Ed.), Risk and resilience in childhood: An ecological perspective (pp. 50-72). Washington, DC: NASW Press. 
International Journal of Child, Youth and Family Studies (2013) 3: 328-336

Ungar, M. (2004). A constructionist discourse on resilience: Multiple contexts, multiple realities among at-risk children and youth. Youth and Society, 35(3), 341-365.

Ungar, M. (2008). Resilience across cultures. British Journal of Social Work, 38(2), 218-235.

Ungar, M. (2011a). Community resilience for youth and families: Facilitative physical and social capital in contexts of adversity. Children and Youth Social Services Review, 33, 17421748.

Ungar, M. (2011b). The social ecology of resilience. Addressing contextual and cultural ambiguity of a nascent construct. American Journal of Orthopsychiatry, 81, 1-17.

Ungar, M. (2012). Social ecologies and their contribution to resilience. In M. Ungar (Ed.), The social ecology of resilience: A handbook of theory and practice (pp. 13-32). New York: Springer.

Ungar, M., \& Liebenberg, L. (2011). Assessing resilience across cultures using mixed methods: Construction of the Child and Youth Resilience Measure. Journal of Multiple Methods in Research, 5(2), 126-149.

Ungar, M., Liebenberg, L., Armstrong, M., Dudding, P., \& van de Vijver, F. J. R. (2013). Patterns of service use, individual and contextual risk factors, and resilience among adolescents using multiple psychosocial services. Child Abuse \& Neglect, 37(2/3), 150159.

Wright, M. O., \& Masten, A. S. (2006). Resilience processes in development. In S. Goldstein \& R. B. Brooks (Eds.), Handbook of resilience in children (pp. 17-38). New York: Springer.

Wyman, P. A. (2003). Emerging perspectives on context specificity of children's adaptation and resilience: Evidence from a decade of research with urban children in adversity. In S. S. Luthar (Ed.), Resilience and vulnerability: Adaptation in the context of childhood adversities, (pp. 293-317). Cambridge, UK: Cambridge University Press.

Yates, T. M., Egeland, B., \& Sroufe, L. A. (2003). Rethinking resilience: A developmental process perspective. In S. S. Luthar (Ed.), Resilience and vulnerability: Adaptation in the context of childhood adversities, (pp. 243-266). Cambridge, UK: Cambridge University Press.

Zeldin, S., Camino, L., \& Mook, C. (2005). The adoption of innovation in youth organizations: Creating the conditions for youth-adult partnerships. Journal of Community Psychology, 33(1), 121-135. 